\title{
From the mouth of babes: Getting vaccinated doesn't have to hurt
}

\author{
Anna Taddio PhD ${ }^{1}$, Andrew F Ilersich ${ }^{1}$, Anthony N Ilersich¹, Jenny Wells ${ }^{2}$
}

A Taddio, AF Ilersich, AN Ilersich, J Wells. From the mouth of babes: Getting vaccinated doesn't have to hurt. Can J Infect Dis Med Microbiol 2014;25(4):196-200.

BACKGROUND: Analgesic interventions are not commonly administered during childhood vaccination, despite the fact that two-thirds of children are afraid of needles and one-tenth are noncompliant with immunization.

OBJECTIVE: To explore children's experiences of vaccination and preferences for analgesia.

METHODS: A total of 17 children (four to 14 years of age) at an independent school in Toronto (Ontario) participated in three focusgroup interviews. The majority had previous experience with pain management interventions during vaccination. Thematic content analysis was used to analyze interview transcripts.

RESULTS: The findings were categorized into three main themes: experience of vaccination; roles and responsibilities regarding pain management; and impact of pain management. Children easily recalled previous vaccinations and discussed fear and distress experienced by themselves and others. Children believed that parents and immunizers should prepare them ahead of time and use interventions to manage and monitor pain. They also wanted adults to support their efforts to lead pain management. Children discussed benefits of managing pain, including reduced unnecessary suffering, improved vaccination experience, reduced risk of developing needle fears and reduced noncompliant behaviours. They were knowledgeable about strategies for reducing pain including distraction, topical anesthetics and injection techniques. They contrasted vaccination with and without pain management, and indicated a preference for pain management.

CONCLUSION: Children reported that managing vaccination pain is important and that analgesic interventions should routinely be used. Incorporating pain management in the process of vaccination has the potential to improve children's experiences with vaccination and promote more positive attitudes and behaviours.

Key Words: Children; Pain management; School-based immunization clinics; Vaccination

$\mathrm{M}$ anaging the pain of vaccine injections in children is clinically important. Recent studies suggest that two of three children are afraid of needles and approximately one of 10 children are noncompliant with immunization as a result of needle fear (1). There is a plethora of research evidence supporting the use of pharmacological, psychological and physical interventions for reducing vaccination pain in children (2-4); however, these interventions are not routinely administered in clinical practice $(5,6)$. This results in children suffering unnecessarily from pain and associated long-term adverse sequelae.

According to the Knowledge-to-Action Framework (7), the successful translation of research knowledge is based on the development of knowledge tools, such as clinical practice guidelines (CPGs), and

\section{De la bouche des enfants : les vaccins n'ont pas besoin de faire mal}

HISTORIQUE : Les interventions analgésiques ne sont pas fréquentes pendant la vaccination des enfants, même si les deux tiers des enfants ont peur des seringues et que le dixième ne se fait pas vacciner.

OBJECTIF : Explorer l'expérience les enfants vis-à-vis de la vaccination et leurs préférences en matière d'analgésie.

MÉTHODOLOGIE : Au total, 17 enfants (de quatre à 14 ans) d'une école indépendante de Toronto, en Ontario, ont participé à trois entrevues au sein de groupes de discussion. La majorité avait déjà profité d'interventions de gestion de la douleur pendant la vaccination. Les chercheurs ont utilisé l'analyse thématique du contenu pour dépouiller la transcription des entrevues.

RÉSULTATS : Les résultats ont été classés en trois grands thèmes : l'expérience de la vaccination, les rôles et responsabilités relatives à la gestion de la douleur et les conséquences de la gestion de la douleur. Les enfants se rappellent facilement les vaccins qu'ils ont déjà reçus et parlent de la peur et de la détresse qu'eux ou d'autres ont ressenties. Les enfants pensaient que les parents et les vaccinateurs devraient les préparer d'avance et recourir à des interventions pour gérer et surveiller la douleur. Ils voulaient également que des adultes les aident dans leurs efforts pour diriger la gestion de la douleur. Les enfants ont parlé des avantages de gérer la douleur, y compris la diminution de souffrances inutiles, une meilleure expérience de la vaccination, la diminution des risques de craindre les seringues et la diminution de la non-adhérence à la vaccination. Ils connaissaient les stratégies pour réduire la douleur, y compris la distraction, les anesthésiques topiques et les techniques d'injection. Ils ont comparé la vaccination accompagnée ou non d'une gestion de la douleur et indiqué leur préférence pour la gestion de la douleur.

CONCLUSION : Les enfants ont souligné l'importance de gérer la douleur de la vaccination et d'utiliser systématiquement des interventions analgésiques. L'intégration de la gestion de la douleur au processus de vaccination pourrait améliorer l'expérience des enfants vis-à-vis de la vaccination et favoriser des attitudes et comportements plus positifs.

their subsequent customization and implementation within the local context. To begin to address the identified knowledge-to-care gap in childhood vaccination pain management, we developed a CPG with recommendations for managing vaccination pain (8). We subsequently tailored and pilot-tested the CPG in different vaccination settings, including school-based public health immunization clinics. Specifically, we incorporated pain management interventions from the CPG and altered the physical environment to reduce fear and pain in children. Analgesic interventions used during vaccination included topical anesthetics and distraction agents (eg, computers, smartphones and books). Modifications in the physical environment, informed in part by discussions with regional public health nurses (9), included: using a private classroom for all injections, and

${ }^{1}$ Clinical, Social and Administrative Pharmacy, Leslie Dan Faculty of Pharmacy, University of Toronto, and Child Health Evaluative Sciences,

The Hospital for Sick Children; ${ }^{2}$ AboutKidsHealth, The Hospital for Sick Children, Toronto, Ontario

Correspondence: Dr Anna Taddio, Leslie Dan Faculty of Pharmacy, University of Toronto, 144 College Street, Toronto, Ontario M5S $3 \mathrm{M} 2$.

Telephone 416-978-8822,fax 416-978-1833, e-mail anna.taddio@utoronto.ca

OPEN ACCESS

This open-access article is distributed under the terms of the Creative Commons Attribution Non-Commercial License (CC BY-NC) (http:// creativecommons.org/licenses/by-nc/4.0/), which permits reuse, distribution and reproduction of the article, provided that the original work is properly cited and the reuse is restricted to noncommercial purposes. For commercial reuse, contact support@pulsus.com 
TABLE 1

\section{Interview guide}

What do you remember about your last vaccination?

What do you think children should know about vaccination?

What do you think adults should know about vaccination?

What do you think helps to reduce pain?

vaccinating children independently and out of view of their peers; hiding anxiety-provoking equipment, such as needles, from view; and providing cookies and juice after vaccination, and pizza at lunchtime. Students provided feedback during the pilot by rating their pain from the procedure. Parents of children scheduled to undergo vaccination consented separately for them to participate in the pilot.

In the present qualitative study, we explored the perceptions of children of different ages and experiences with vaccination pain management at an independent school in Toronto (Ontario) one year after the pilot CPG-implementation project was conducted at the school.

\section{METHODS}

Participants and setting

Participants were selected using the qualitative sampling technique of maximum variation sampling $(10)$. Students $(n=47)$ from junior kindergarten to grade 8 attending an English, nondenominational, independent/private (ie, requiring tuition payment) school in Toronto, Ontario were eligible. Parents received notification from the school principal that researchers were planning to interview children regarding their experiences with vaccination, and they signed a written consent form allowing the interviews to be videotaped. Ethics approval was obtained from The Hospital for Sick Children's Research Ethics Board (Toronto, Ontario).

Three separate focus group sessions, each lasting approximately $30 \mathrm{~min}$, were held at the school on the study day (June 4, 2010). All sessions were moderated by the same interviewer using a semistructured interview guide (Table 1). The first focus group session was held outside in the school playground with six students from junior kindergarten to grade 5 . The second session was held in a classroom with eight students from grades 6 to 8. The third was held in the principal's office with three students from grades 4 to 8 . The vice principal, who facilitated the pilot testing in the previous year, provided feedback separately.

All interviews were later transcribed verbatim by an independent transcriptionist. Qualitative content analysis was used to generate codes inductively from the transcripts (10). Line-by-line coding was performed independently by two researchers, and disagreements were discussed until consensus was reached. The researchers met to review and revise the coding structure. The results were reviewed with students at the school (ie, member checking) and the vice principal.

\section{Characteristics of participants}

\section{RESULTS}

Collectively, parents of 17 students signed consent forms for their children to participate. The children were four to 14 years of age and nine $(53 \%)$ were boys. Characteristics of the children are shown in Table 2. The grade 8 students had participated in the pilot test in the previous year, when they were in grade 7 .

The findings from all three focus group sessions were categorized into three main themes: experience of vaccination; roles and responsibilities regarding pain management; and impact of pain management (Figure 1).

\section{Experience of vaccination}

All students recalled previous vaccinations and discussed fear and distress experienced by themselves and others, primarily siblings, during vaccination:
TABLE 2

Characteristics of participants*

\begin{tabular}{lccc}
\hline Participant & $\begin{array}{c}\text { Focus group } \\
\text { session }\end{array}$ & Sex & Grade \\
\hline 1 & 1 & Boy & JK \\
2 & 1 & Boy & 1 \\
3 & 1 & Boy & 4 \\
4 & 3 & Girl & 4 \\
5 & 3 & Boy & 4 \\
6 & 1 & Boy & 5 \\
7 & 1 & Girl & 5 \\
8 & 1 & Girl & 5 \\
9 & 2 & Girl & 6 \\
10 & 2 & Boy & 7 \\
11 & 2 & Boy & 7 \\
12 & 2 & Boy & 8 \\
13 & 2 & Girl & 8 \\
14 & 2 & Girl & 8 \\
15 & 2 & Boy & 8 \\
16 & 2 & Girl & 8 \\
17 & 3 & Girl & 8 \\
\hline
\end{tabular}

${ }^{*}$ Caucasian (n=13); Asian (n=3); Black $(n=1)$. JK Junior kindergarten

We would always be scared, like we would try to hide in our room or run away or something because we wouldn't want the sharp sensation in our arm. (P14)

Students reported that vaccinations were scary because they were painful:

It scares me because they hurt. (P7)

Some students reported disliking the needle:

It's just freaky to see something sharp or long get injected into you. (P9)

Pain was described as an individual experience:

Well everyone has their own feelings, right? And they feel the needle differently. (P14)

Perceptions of pain were reported to be influenced by age and previous experience. In some cases, fear worsened with increasing age and experience:

I feel a little bit more pain than before. (P16)

In other cases, it diminished:

When I was little, I used to hate it, but now I'm okay with it. (P9)

Several children discussed how their thoughts could modify their pain:

I was thinking in my mind what if the needle was too long and it went right through my arm? Your imagination makes you go crazy! (P9)

Some students questioned whether health care providers cared about them because they did not address their pain:

I remember...they came in to give them a shot. And what they would do is that they had a table and a couple of nurses sitting at the table. And they would have the whole school line up and the nurse gave them their shot even if they were screaming. Some girls couldn't even take it and the nurse would just give them the shot and tell them to go. That's it. I guess they just didn't care. They just give the person the shot and get through it quickly. (P14)

Students that participated in the pilot also commented on the ability to provide feedback about their pain experience:

I like how we got to evaluate how it felt....it's important to get peoples' opinions on how the needle felt. (P14) 


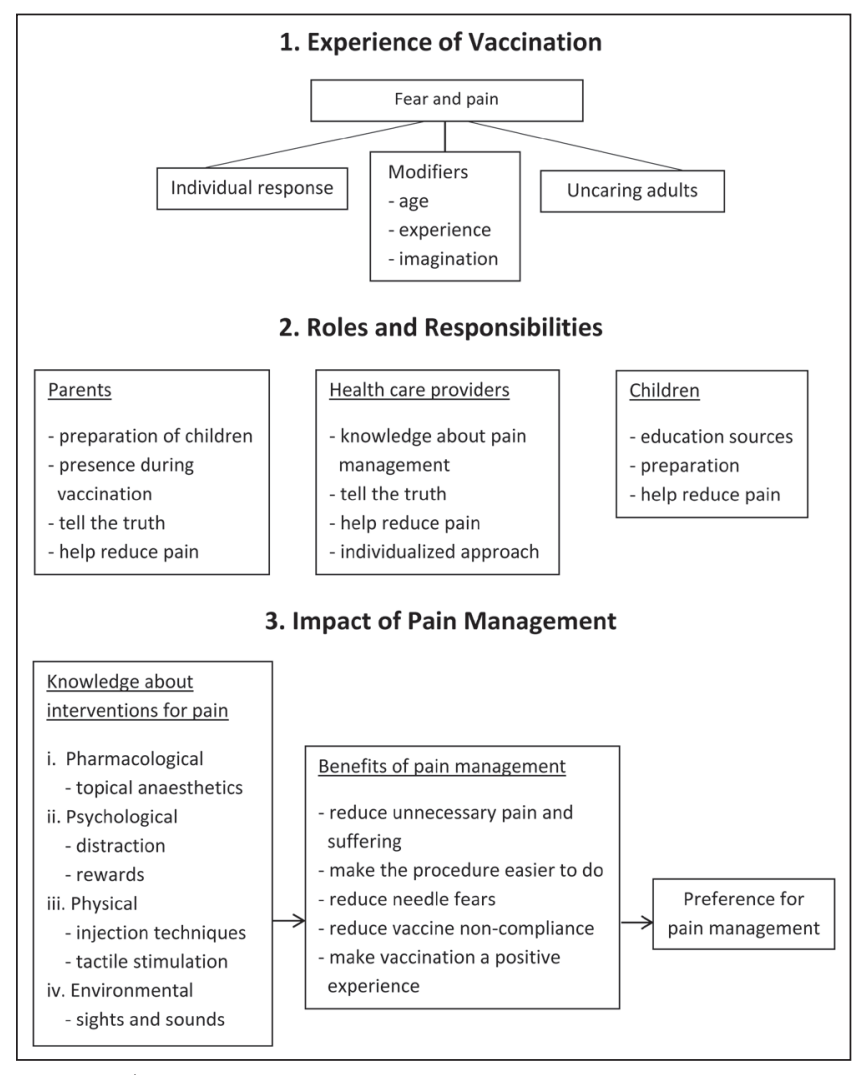

Figure 1) Key themes that emerged from the study

None of these students reported ever being asked about their pain before.

\section{Roles and responsibilities regarding pain management}

All students agreed that health care providers and parents are responsible for helping children feel less pain during vaccination and that interventions to mitigate pain should be routinely used.

Students were aware of why they needed to be immunized:

To protect against diseases and viruses. (P12)

However, they felt they should be better prepared for upcoming vaccinations. This included knowing why vaccines need to be injected:

...why (it has) to be poked in my arm, and I couldn't take a

tablet with a glass of water and have the same effect. (P12)

and how the injection would feel:

...if they know (how they feel), they know it's nothing more

horrible, so they don't imagine something worse. (P12)

They also wanted to be able to bring items to help them cope:

You have to know about it and prepare for it...like maybe you'll

bring a toy or something like bubbles. (P3)

Students reported that neither parents nor doctors should lie to them about the pain:

It doesn't help if they say you will feel no pain at all, it's just a big lie. (P16)

When they lie to you and then it does hurt, you're less likely to trust them later on. (P11)

Students reported that parents should be present to help them but that they should not act afraid themselves because they could transmit their feelings to children:

Yeah, and if the parents are tense, the child will think, Oh my parents are freaked, I guess this is really going to hurt. (P7)

With respect to health care providers specifically, students reported they should be knowledgeable and use different pain-relieving methods:
What we're all trying to say is that doctors should know methods for us so that we would experience pain less....so going to the doctor shouldn't be such a painful thing to do. (P14)

Students reported that the school pilot and previous experiences with vaccination were their major sources of information about how to reduce pain. Some younger students learned from others that participated in the pilot. Students that were knowledgeable about pain management interventions talked about taking charge of their pain and leading their own pain management:

The most recent time I got vaccinated, I used the cream, used my laptop. (P12)

One student described being frustrated by instances whereby her efforts to reduce pain were not supported by health care providers:

I would tell them that sometimes the only way for the pain to get out of me is to pinch myself, or pinch my knee. The nurses or doctors always say to me to relax, and I can't do that. I was pinching myself and they saw me tense, and they didn't know what I'm doing and they tell me to relax so I can't do my thing. (P16)

The same student recommended health care providers ask children about their preferences:

They should actually first ask the patient of what way they have to relieve the pain, so that they could tell them, for example, they like pinching or listening to music or something. (P16)

\section{Impact of pain management}

All students agreed it was important to treat pain. The students offered many reasons for treating pain including: preferences for individuals not to have pain; reducing unnecessary pain; making the procedure easier by reducing 'freaking out' kids, or kids that were fighting or running away; reducing needle phobia; and reducing vaccine noncompliance by parents and children.

Many students were knowledgeable of strategies for reducing pain including distraction, topical anesthetics and injection techniques. Students mentioned numerous distraction agents to "draw attention somewhere else" (P4), including talking, joking, counting, imagery, reading, and playing with toys, bubbles, windmills, dolls and electronic devices. Students also talked about blocking out environmental cues:

Don't ever look at the needle, it hurts more. (P15)

...get my mind off the needle and other people chatting in the background. (P12)

Some students described how the injection technique could influence pain:

Put it in and take it out as quickly as possible. I had a nurse take the needle and wiggle it in my arm for a bit and then withdraw it really slowly and it hurts more. (P17).

A few students described concurrent squeezing, pinching or rubbing the skin to provide a competing sensation to the needle:

What my dad does is he squeezes our hands. (P9)

Students also mentioned rewards:

Getting a reward after is helpful. (P15)

They give you a lollipop after, and that would be the only reason that I go and get my shot. (P9)

Students contrasted vaccination with and without pain management and indicated a preference for pain management:

...better if have something to take away the pain...I didn't feel it. (P3).

Students who participated in the pilot reported having positive experiences and laughing about it later. One student with a fear of needles indicated the fear diminished with adequate pain management: 
I was given the numbing cream and some techniques for distraction and when I got the needle it didn't hurt as much. I didn't really mind them so much anymore. (P12)

The same student however reported that pain management was needed for successful vaccination:

I don't think I can do it without the cream. (P12)

One student who was previously unaware of available pain management interventions indicated she wanted topical anesthetics to be used the next time:

Maybe if they put some numb cream or something so you couldn't feel it, because when I got my needle I was so freaked out that I started crying a lot. (P4)

\section{DISCUSSION}

Children's pain during vaccination has been traditionally underestimated, underprioritized and undertreated, contributing to negative experiences for children and their families and future noncompliance with immunization (11). The present study sought to offer new information and a general view of the experiences of children undergoing vaccination. We included children of different ages attending a school that participated in a pilot project involving implementation of pain management during school-based public health immunization clinics to capture a full range of attitudes and perspectives. We found that children were concerned about pain during vaccination and wanted health care providers and parents to help reduce it. Children were cognizant of pain management interventions and the importance of treating pain, and indicated that pain management should be a routine part of vaccination.

The results confirm earlier reports that children regard needle procedures as frightening and painful, and are preoccupied with pain $(9,12-17)$. They also provide new information regarding children's experiences with implementation of the CPG in a school setting. Children remarked on the stark contrast in their experiences when their pain was managed versus when it was not managed. They unanimously agreed that pain management should be a standard part of the procedure. Importantly, their recalled memories were positive when vaccinated with the benefit of analgesia. This has implications for their reactions to and acceptance of future painful procedures (18) and suggests that addressing environmental and process factors in school and community clinics can significantly improve children's experiences.

When pain was adequately managed and assessed, students believed that health care providers cared about them. Students interpreted health care provider inattention to pain as an indication that they did not care about them. They were also skeptical of individuals that told them that the injection would not hurt. This is consistent with previous studies in children undergoing repeated needle procedures whereby increased levels of fearfulness and distrust of adults, particularly health care providers, was observed $(17,19,20)$. In addition, a lower sense of control over health has been reported $(19,20)$. Considering the repeated nature of vaccination and the continual increase in the number of vaccine injections being administered to individual children over time, more attention should be devoted to the effects of pain on aspects of children's emotional health and wellbeing.

In addition, children reported on the individuality of the pain experience, and that they valued preparation and tailored approaches to pain management. These factors should, therefore, be taken into consideration by parents and health care providers administering vaccinations to children. Children correctly identified evidence-based pain management interventions including topical anesthetics, distraction, injection techniques and tactile stimulation (8). They also correctly identified factors that increase pain perception, such as anxious parents (11). Based on these results, children appear interested and capable of learning about ways to control their pain during vaccination.
At present, pain management interventions are not routinely incorporated across the various vaccination settings. The present findings have important implications for stakeholders involved in immunization including children, health care providers, policy makers, parents and teachers. By simply providing children and parents with information about how to mitigate pain ahead of time, and making alterations to the physical environment and the process of vaccination, children's concerns about pain can be addressed $(9,11)$. This has the potential to significantly improve children's vaccination experience, attitudes toward health care providers and vaccination, and future compliance with vaccination. Managing children's pain can also increase their feelings of security and self-efficacy. This, in turn, will increase their confidence in their self-coping ability, and promote involvement and responsibility in other aspects of health.

There are several limitations that warrant discussion. First, only a single independent academic school in Toronto was included and it is possible that not all children's perspectives were identified. It is important to note, however, that children from across the Greater Toronto Area attend the school, rather than only those from a specific neighbourhood. In addition, the students come from a variety of ethnic backgrounds, reflective of the multicultural background of children in the Greater Toronto Area. Second, the responses of children who participated in the pilot may have been influenced by a desirability to respond in a socially desirable way (eg, make the issue of pain larger). However, this is unlikely to have played a major role because the results are consistent with previous studies demonstrating the prominence of pain as the defining feature of the immunization experience for children. In addition, the perspectives of children who did and did not have previous experience with pain management during immunization were specifically sought in the present study to capture many different perspectives. Third, the changes to the school-based clinic that occurred in the study school could be accommodated by school administrators and the regional public health unit; however, they may be more difficult to implement in other schools and/or public health units, limiting the generalizability of the results. A collaborative relationship between school administrators and public health officials and a childfocused view is required to realize changes to the process of schoolbased vaccinations that will improve the vaccination experience for children. Fourth, the analgesic supplies (topical anesthetics and some distraction agents) and food (cookies, juice, pizza) from the pilot were provided by investigators. Investigators also led the implementation of pain management interventions. Future pain management implementation projects should consider enlisting the help of parents with organization of clinic days, including acquisition of necessary supplies and execution of pain management interventions. This will increase their engagement and participation and enable them to share in their children's positive vaccination experiences. We have developed educational resources for parents, including an educational video and pamphlet (available at www.immunize.ca/en/parents/pain.aspx) to address gaps in their knowledge about evidence-based analgesic interventions (21). We recommend that complementary educational resources be developed specifically for children. Such resources could incorporate general information about vaccination, and be embedded within the school curriculum, allowing students and staff to benefit.

The present study has many strengths. The credibility of the findings is improved by the focus group design, which allowed for a broad range of information to be identified. The group environment allowed children to interact not only with the moderator, but with one another, allowing group norms and attitudes to arise. Participants are often more forthcoming in describing their attitudes and experiences in the presence of those who are their 'peers' and will often reflect and elaborate on their own views when they hear others put forth similar or divergent views. The study included a broad representation of children with respect to age, sex and previous experience with and without pain management during vaccination, ensuring that a wide range of perspectives and experiences were described. In addition, several other design features ensured that data collection and analysis were valid, including: use 
of a single trained interviewer and interview guide, transcribing videotaped interviews verbatim and double-checking all recordings, performing the analysis with two researchers, and verifying the results with students and the vice principal. A conventional approach to content analysis was performed, whereby preconceived categories were avoided. Rather, the knowledge generated from the analysis were based on participants' unique perspectives and grounded in the actual data.

\section{CONCLUSION}

Pain is the primary concern of children undergoing vaccination. Efforts to mitigate pain are recommended to improve the vaccination experience for children. To assist in the dissemination of these findings, video footage from the present study has been incorporated in videos about pain management intended for public use produced by the authors, in partnership with AboutKidsHealth at The Hospital for Sick Children, Immunize Canada and the Canadian Paediatric Society, available at www.immunize.ca/en/parents/pain.aspx and www.sickkids.ca/Learning/ SpotlightOnLearning/profiles-in-learning/help-eliminate-pain-in-kids/ index.html. We recommend additional research aimed at scaling up

\section{REFERENCES}

1. Taddio A, Ipp M, Thivakaran S, et al. Survey of the prevalence of immunization non-compliance due to needle fears in children and adults. Vaccine 2012;30:2807-12.

2. Taddio A, Ilersich AL, Ipp M, Kikuta A, Shah V, HELPinKIDS Team. Physical interventions and injection techniques for reducing injection pain during routine childhood immunizations: Systematic review of randomized controlled trials and quasi-randomized controlled trials. Clin Ther 2009;31(Suppl 2):S48-76.

3. Shah V, Taddio A, Rieder MJ, HELPinKIDS Team. Effectiveness and tolerability of pharmacological and combined interventions for reducing injection pain during routine childhood immunizations: Systematic review and meta-analyses. Clin Ther 2009;31(Suppl 2):S104-51.

4. Chambers CT, Taddio A, Uman LS, McMurtry CM, HELPinKIDS Team. Psychological interventions for reducing pain and distress during childhood immunizations: A systematic review. Clin Ther 2009;31(Suppl B):S77-103.

5. Taddio A, Manley J, Potash L, Ipp M, Sgro M, Shah V. Routine immunization practices: Use of topical anesthetics and oral analgesics. Pediatrics 2007;120:e637-43.

6. Parvez E, Stinson J, Boon H, Goldman J, Shah V, Taddio A. Mothers' beliefs about analgesia during childhood immunization. Paediatr Child Health 2010;15:289-93.

7. Graham ID, Logan J, Harrison MB, et al. Lost in knowledge translation: Time for a map? J Contin Educ Health Prof 2006;26:13.

8. Taddio A, Appleton M, Bortolussi B, et al. Reducing the pain of childhood vaccination - an evidence-based clinical practice guideline. CMAJ 2010;182:E843-55.

9. Kikuta A, Gardezi F, Dubey V, Taddio A. Practices and perceptions about pain and pain management during routine childhood immunizations: Findings from a focus-group study with nurses working in Toronto Public Health. Can J Infect Dis Med Microbiol 2011;22:1-6.

10. Sandelowski M. Whatever happened to qualitative description? Res Nurs Health 2000;23:334-40. implementation of the CPG about pain management across the various vaccination settings and evaluating the impact on children's pain experience and compliance with immunization.

ACKNOWLEDGEMENTS: The authors thank the parents for granting permission for their children to participate, and the children for their participation. In addition, the authors thank school administrators (Ms Vee Ledson, Mrs Mary Kindos) and Associate Medical Officer of Health for Toronto Public Health, Dr Vinita Dubey, and public health nurses at Toronto Public Health for facilitating implementation of the clinical practice guideline about vaccination pain management during the schoolbased immunization clinics at the study school.

DISCLOSURES: This study was partially funded by the Mayday fund. The funding agency had no input into the study design, conduct, analysis or preparation of the manuscript, and did not participate in the decision to submit the findings for publication. Dr Taddio receives study funding from Pfizer and study supplies from Ferndale and Natus. The authors have no other conflicts of interest to declare.

11. Taddio A, Chambers C, Halperin S, et al. Inadequate pain management during childhood immunization: The nerve of it. Clin Ther 2009;31(Suppl 2):S152-67.

12. Cummings EA, Reid GJ, Finley GA, McGrath PJ, Ritchie JA. Prevalence and source of pain in pediatric inpatients. Pain 1996;68:25-31.

13. Ellis JA, Sharp D, Newhook K, Cohen J. Selling comfort: A survey of interventions for needle procedures in a pediatric hospital. Pain Manag Nurs 2004;5:144-52.

14. Humphrey GB, Boon CM, van Linden van den Heuvell GF, van de Wiel HB. The occurrence of high levels of acute behavioral distress in children and adolescents undergoing routine veinpunctures. Pediatrics 1992;90:87-91.

15. Brabin L, Roberts SA, Stretch R, et al. A survey of adolescent experiences of human papillomavirus vaccination in the Manchester study. Br J Cancer 2009;101:1502-4.

16. Bernard DM, Cooper Robbins SC, McCaffery KJ, Scott CM, Skinner SR. The domino effect: Adolescent girls' response to human papillomavirus vaccination. Med J Aust 2011194:297-300.

17. Benin AL, Wu AC, Holmboe ES, Shapiro ED, Anyan W. How can we communicate about vaccines with adolescents and their parents? Clin Pediatr (Phila) 2010;49:373-80.

18. Von Baeyer CL, Marche TA, Rocha EM, Salmon K. Children's memory for pain: Overview and implications for practice. J Pain 2004;5:241-9.

19. Rennick JE, Johnston CC, Dougherty G, Platt R, Ritchie JA. Children's psychological responses after critical illness and exposure to invasive technology. J Dev Behav Pediatr 2002;23:133-144.

20. Salmela M, Aronen ET, Salantera S. The experience of hospitalrelated fears of 4- to 6-year-old children. Child Care Health Dev 2011;37:719-26.

21. Taddio A, Shah V, Leung E, et al. Knowledge translation of the HELPinKIDS clinical practice guideline for managing childhood vaccination pain: Usability and knowledge uptake of educational materials directed to new parents. BMC Pediatrics 2013;13:23. 


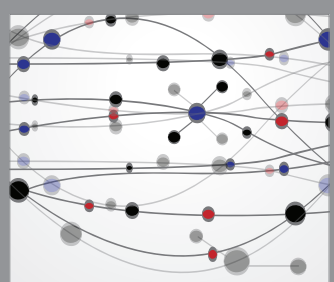

The Scientific World Journal
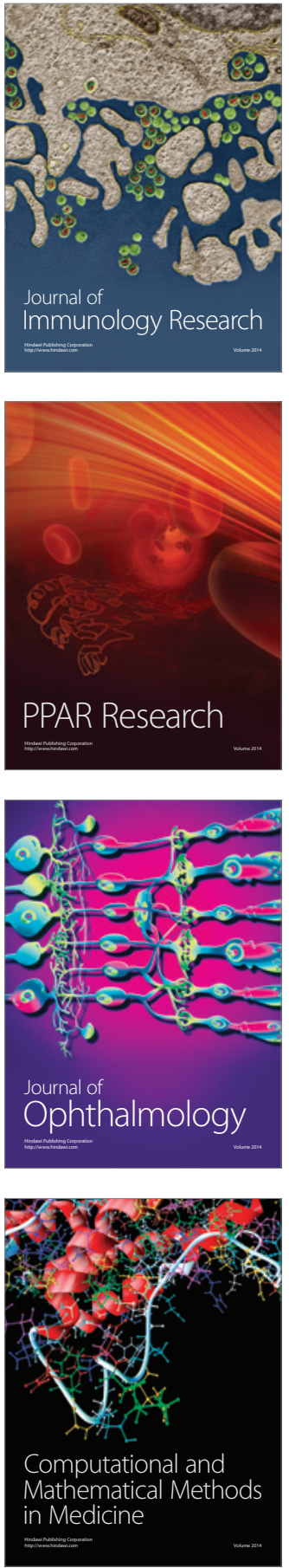

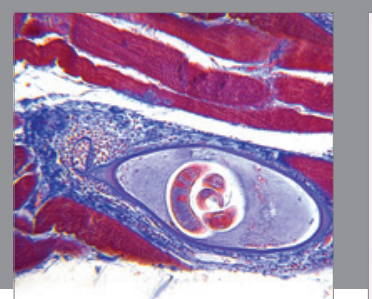

Gastroenterology Research and Practice

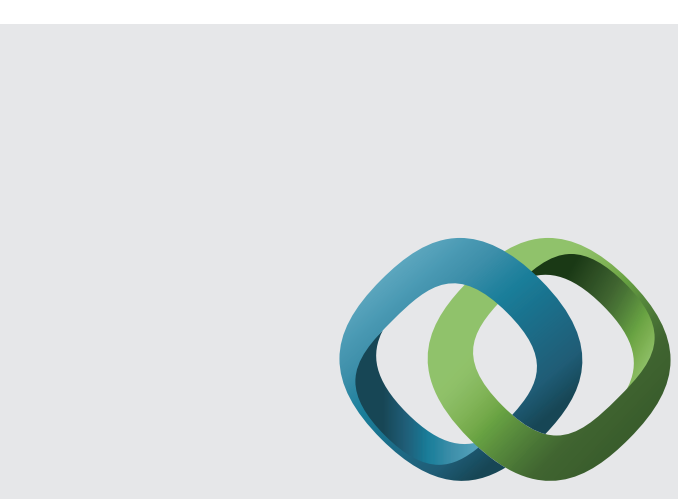

\section{Hindawi}

Submit your manuscripts at

http://www.hindawi.com
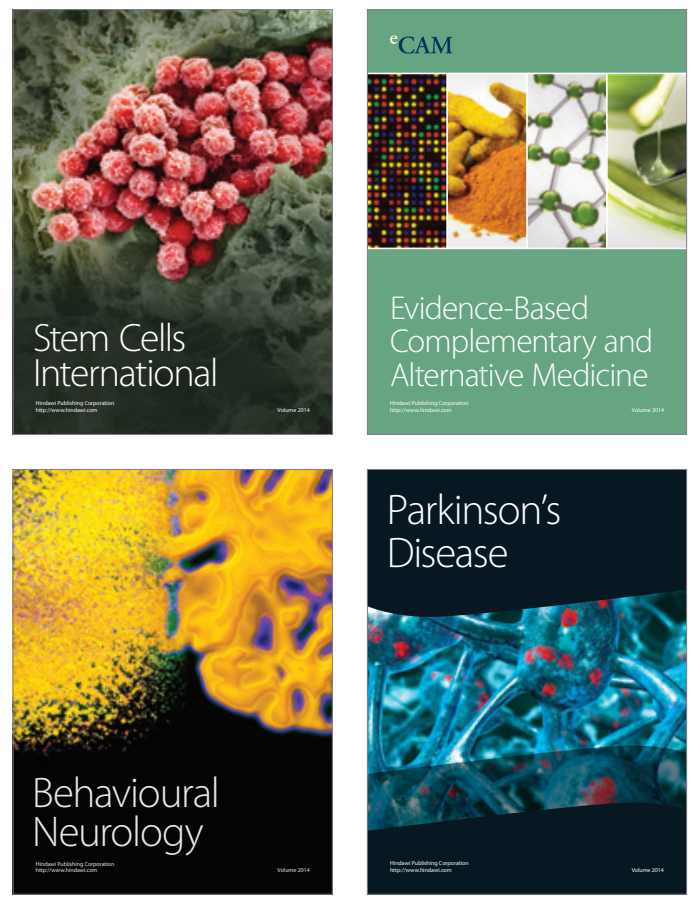
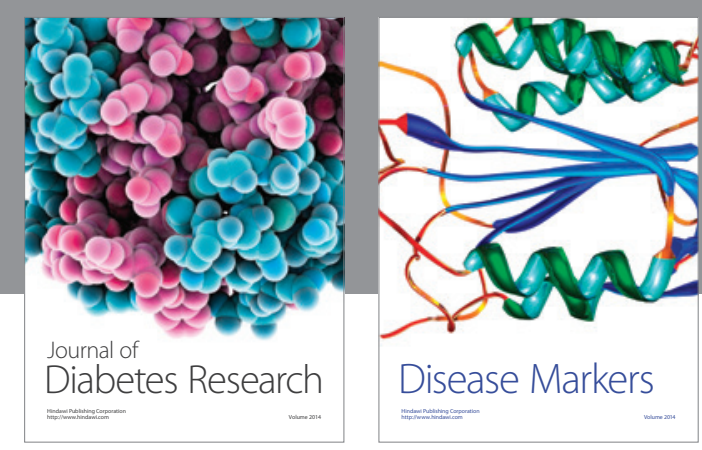

Disease Markers
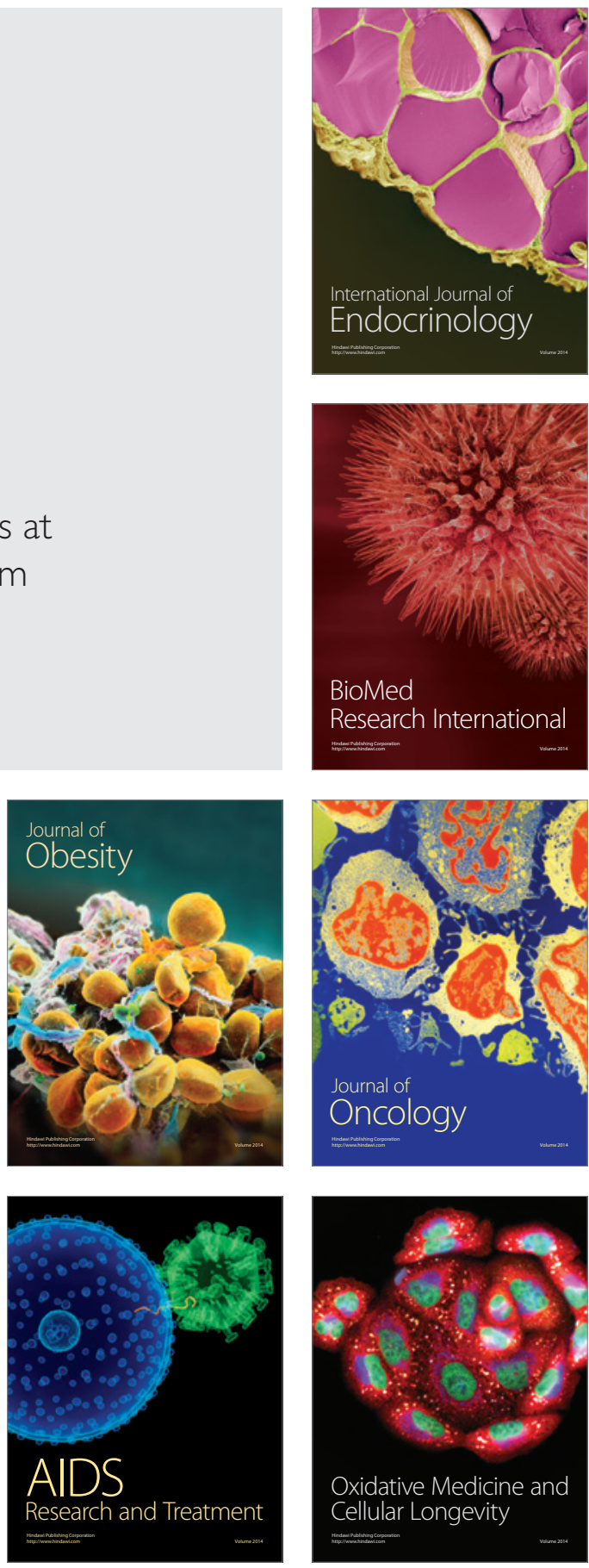